\title{
Inhibition of the adherence of Pseudomonas aeruginosa to epithelial cells by IgG subclass antibodies
}

\author{
MARY MORRIN and D. J. REEN* \\ Children's Research Centre, Our Lady's Hospital for Sick Children, Crumlin, Dublin 12
}

\begin{abstract}
Summary. A beneficial role of the antibody response to Pseudomonas aeruginosa seen in cystic fibrosis (CF) patients has not been established. We investigated a possible role for these antibodies as inhibitors of the adherence of $P$. aeruginosa to mammalian cells. An adhesion model system was used, employing buccal epithelial cells in an enzyme-labelled immunoassay procedure on microtitration plates. Total levels of IgG, IgA, IgM and the four IgG subclasses were estimated in $11 \mathrm{CF}$ patients and 10 healthy controls. Most of the CF patients demonstrated increased levels of all these immunoglobulin types. Sera from seven patients with elevated serum IgG were observed to cause greater inhibition of the adherence of $P$. aeruginosa to buccal cells than were the sera from four $\mathrm{CF}$ patients with low serum $\mathrm{IgG}$ and from ten healthy controls. Nevertheless, the levels of individual anti- $P$. aeruginosa IgG subclass antibodies varied amongst the patients and did not correlate with the degree of inhibition of bacterial adherence. Negative affinity chromatography was used to obtain antibody fractions enriched for $\mathrm{IgG} 1, \mathrm{IgG} 2$ or IgG4 and protein A-sepharose chromatography was used to isolate IgG3 antibodies from CF patients. The IgG1-, IgG2-, or IgG4enriched fractions similarly inhibited the adherence of $P$. aeruginosa in the test system, whereas three of five IgG3-enriched fractions from CF patients had no greater effect on adhesion than did IgG from control individuals.
\end{abstract}

\section{Introduction}

Despite aggressive antibiotic therapy, chronic infection with Pseudomonas aeruginosa remains the major source of morbidity and mortality amongst patients with cystic fibrosis (CF). Bacterial adherence is a pre-requisite to colonisation in this infection, as in any other, and both the receptors and the adhesins have been studied. Specific disaccharides that are commonly found in mucins ${ }^{1}$ have been shown to bind $P$. aeruginosa, as have the neutral glycosphingolipids of epithelia. ${ }^{2,3}$ Binding of $P$. aeruginosa to mucins from $\mathrm{CF}$ sputum has been demonstrated recently to be non-specific, contrary to what was once believed. ${ }^{4}$ The role of pili has been investigated by many groups. Purified pilin and monoclonal antibodies (MAbs) directed against peptide sequences within pilin have both been shown to inhibit adherence of $P$. aeruginosa to human buccal epithelial cells ${ }^{5,6}$ and a human epithelial cell-binding domain has been identified in the C-terminal region of the pilin protein. ${ }^{7}$ Nevertheless, free pili fail to inhibit entirely the adhesion of $P$. aeruginosa to human cells in competition experiments, indicating the participation of other bacterial

Received 17 Aug. 1992; revised version accepted 4 June 1993.

* Correspondence should be sent to Dr D. J. Reen. adhesins in the binding process. Data supporting a role for muco-exopolysaccharide in adherence of mucoid $P$. aeruginosa have been reported ${ }^{8}$ and recent evidence suggests that exo-enzyme $\mathrm{S}$ may be a major adhesin, as it binds to a series of glycosphingolipids with the same specificity as to whole $P$. aeruginosa cells. ${ }^{9}$ In support of this view, it was noted that addition of free exo-enzyme $\mathrm{S}$ and antibodies to exoenzyme $\mathrm{S}$ inhibited adherence of $P$. aeruginosa. ${ }^{9}$

Although a hyperimmune response is characteristically seen in CF patients, this is ineffective in eliminating pseudomonal infection. Indeed, and paradoxically, high IgG titres to $P$. aeruginos $a$ antigens correlate with worsening pulmonary disease. ${ }^{10}$ Thus, a beneficial role for the anti-pseudomonal antibody response has not been established. The IgG subclass response to $P$. aeruginosa has formed the basis of many investigations. The relative amounts of the different isotypes have been correlated with pulmonary function and stage of infection, ${ }^{11}$ deficiency in opsonophagocytosis $^{12,13}$ and efficacy in immunoprotection. ${ }^{14}$

This present study describes the use of negative affinity chromatography to obtain enriched fractions of each of the individual IgG subclasses and the subsequent assessment of the ability of each subclass to inhibit adhesion of $P$. aeruginosa to buccal epithelial cells. 


\section{Materials and methods}

\section{Bacterial strain and growth conditions}

A non-mucoid clinical strain of $P$. aeruginosa isolated from a CF patient was used throughout the investigation. This strain has been shown previously to bind strongly to buccal epithelial cells in an adhesion model system. ${ }^{15}$ Cultures were maintained on tryptone soya agar at $4^{\circ} \mathrm{C}$.

\section{Patients}

All CF patients were adults, aged from 16 to 38 years, with chronic $P$. aeruginosa infection. Sera from age-matched healthy individuals were used as controls.

\section{Quantification of immunoglobulin isotypes}

Wells in microtitration plates (Dynatech M129B) were coated overnight at $4^{\circ} \mathrm{C}$ with anti-human $\mathrm{IgG}$, IgA or IgM MAbs (Cappell, Organon Teknika, Westchester, PA, USA), applied as $100 \mu$ l amounts at concentrations to $10 \mathrm{mg} / \mathrm{L}$ in $0 \cdot 1 \mathrm{M}$ carbonate-bicarbonate buffer, $\mathrm{pH} 9 \cdot 6$. Subsequently, the plates were washed with $0 \cdot 1 \mathrm{M}$ phosphate-buffered saline, $\mathrm{pH} 7 \cdot 2$, containing Tween 20, $0.05 \%$ (PBS-T). Either sera from patients or standard IgG, IgA or IgM preparations (Binding Site, Birmingham), were then added. After incubation for $1 \mathrm{~h}$ at room temperature (RT) followed by washing, horseradish peroxidase (HRP)conjugated anti-human IgG, IgA or IgM MAb (Tago, Burlingame CA, USA) was added to the appropriate wells and the plates were incubated for $1 \mathrm{~h}$ at RT. The plates were then washed, after which ortho-phenylene diamine (OPD) substrate was added. After further incubation for exactly $30 \mathrm{~min}$ at RT, the absorbance at $450 \mathrm{~nm}$ was read with a Microplate Reader (Bio-tek, Winoski, VT, USA). The concentrations of IgG, IgA and IgM in the sera from patients were estimated from the reference curves constructed from the data obtained with the standard IgG, IgA and IgM preparations.

\section{IgG subclass estimation}

An ELISA procedure was developed for the quantification of IgG subclasses. Subclass-specific MAbs as follows were used, at concentrations of $10 \mathrm{mg} / \mathrm{L}$ in $0.1 \mathrm{M}$ carbonate-bicarbonate buffer, $\mathrm{pH} 9 \cdot 6$, to coat the wells of microtitration plates. IgG1 (Clone 6001; Unipath Ltd, Basingstoke, Hants); IgG2 (Clone 6014; Binding Site); IgG3 Clone 6050; Unipath); IgG4 (Clone 6023; Binding Site). After incubation overnight at $4^{\circ} \mathrm{C}$, the plates were washed with PBS-T, and non-specific binding was blocked by incubation with bovine serum albumin $1 \%$ in PBS-T for $3 \mathrm{~h}$ at $37^{\circ} \mathrm{C}$. IgG-subclass standard (Binding Site) or sera from patients diluted in PBS-T were then added to the plates, which were incubated for $1 \mathrm{~h}$ at $37^{\circ} \mathrm{C}$.
Subsequently, HRP-conjugated anti-human IgG $\mathrm{MAb}$ (Cappell) was added and binding reactions were detected with OPD substrate as described above.

\section{IgG subclass fractionation}

Purification and coupling of subclass-specific antibodies. The four MAbs used in the affinity purification of IgG immunoglobulin subclasses were obtained as ascites fluids from Recognition Sciences Ltd, Birmingham, and comprised Clones TM-10 (anti-IgG 2, 3, 4), HP6019 (anti-IgG1, 3, 4), OF3 (anti-IgG1, 2, 3) and HP6025 (anti-IgG4). The method followed for their purification from ascites fluid was essentially that of Persson, ${ }^{16}$ with some modifications. Briefly, the preparation samples were dialysed against three changes of $0.02 \mathrm{M}$ Tris- $\mathrm{HCl}$ buffer, $\mathrm{pH} 7 \cdot 6$, before purification of the IgG fraction on a DEAE-Affi Gel Blue column (BioRad, Hemel Hempstead, Herts), with gradient elution at $30 \mathrm{ml} / \mathrm{h}$, The elution buffer was $0.02 \mathrm{M}$ Tris- $\mathrm{HCl}, \mathrm{pH} \mathrm{7.6}$, applied as steps containing $0,20,60,100$ and $500 \mathrm{~mm} \mathrm{NaCl}$. The monoclonal IgG eluted at a $\mathrm{NaCl}$ concentration of $60 \mathrm{~mm}$. The appropriate fractions were then concentrated by ultrafiltration (Centricon Units, Amicon Ltd) and washed several times with $0 \cdot 1 \mathrm{M}$ sodium bicarbonate buffer, pH $8 \cdot 1$, containing $0 \cdot 5 \mathrm{M} \mathrm{NaCl}$. Each purified antibody was then coupled to $\mathrm{CNBr}$-activated Sepharose 6B (Pharmacia LKB, Milton Keynes, Bucks) used according to the manufacturer's instructions. The coupling ratio was c. $7 \mathrm{mg}$ of antibody $/ \mathrm{ml}$ of gel.

$I g G$ isolation and Ig $G$ subclass fractionation. The IgG fractions of patient and control sera were isolated by protein G-sepharose chromatography. Columns containing $1 \mathrm{ml}$ of the pre-made gel (Pharmacia) were equilibrated with $20 \mathrm{~mm}$ sodium phosphate buffer, $\mathrm{pH} 7 \cdot 6$. Serum samples $(1 \mathrm{ml})$ were then applied. After washing with the equilibration buffer the bound IgG was eluted with $0 \cdot 1 \mathrm{M}$ glycine, $\mathrm{pH} 2 \cdot 8$. Fractions were neutralised with $2 \mathrm{M}$ Tris- $\mathrm{HCl}, \mathrm{pH} 8 \cdot 0$, and were used directly in the adhesion model or were purified further by negative affinity chromatography as described below.

For isolation of individual IgG subclasses, columns containing $1 \mathrm{ml}$ of sepharose-linked anti-IgG subclass antibody were prepared as described above, and were equilibrated with $0.02 \mathrm{M}$ Tris- $\mathrm{HCl}, \mathrm{pH} 7 \cdot 8$, containing BSA $0.01 \% \quad 0.5 \mathrm{M} \mathrm{NaCl}$ and sodium azide $0.01 \%$. Patient or control serum IgG fractions were applied, and the unbound subclass of interest was eluted with the equilibration buffer. The purifications of IgG 1 and IgG4 were achieved in single-step procedures. A column substituted with anti-IgG4 from Clone MP6025 (anti-IgG4) was incorporated as a preliminary step in the IgG2 procedure, as large amounts of contaminating IgG4 otherwise remained. Yields from negative affinity columns tended to be quite low $(20-40 \%)$ but the extent of enrichment was high, with $>90 \%$ purity attained as assessed by ELISA. 
IgG3 fractions were obtained with a protein Asepharose column which had poor affinity for IgG3. The IgG preparation was applied and the unbound IgG3 was collected with $20 \mathrm{~mm}$ sodium phosphate buffer, $\mathrm{pH} 7 \cdot 8$, as the eluent. The column was washed with $0 \cdot 1 \mathrm{M}$ glycine, $\mathrm{pH} 2 \cdot 8$, and then re-equilibrated. The yields were low $(20 \%)$ but over $80 \%$ purity was attained.

\section{Adhesion model system}

Buccal epithelial cells were collected on sterile cotton swabs from healthy adult volunteers and suspended in phosphate-buffered saline (PBS). The cells were pooled, washed five times $(1000 \mathrm{~g}, 5 \mathrm{mins})$, and resuspended in PBS at a concentration of approximately $10^{5} / \mathrm{ml}$. Samples $(100 \mu \mathrm{l})$ of this suspension were added to a microtitration plate, left for $10 \mathrm{~min}$ at $\mathrm{RT}$, and then centrifuged at $1000 \mathrm{~g}$ for $10 \mathrm{~min}$. The supernates were aspirated carefully with a multichannel pipette and the remaining monolayer of epithelial cells was incubated overnight at $37^{\circ} \mathrm{C}$ to dry, then fixed by treatment with glutaraldehyde $0.25 \%$ for $10 \mathrm{~min}$. After this and all subsequent steps, the wells were washed three times with PBS. The epithelial cells were treated with BSA solution $1 \%$ for $1 \mathrm{~h}$ at RT to block non-specific binding of bacteria. $P$. aeruginosa suspensions $\left(100 \mu \mathrm{l}\right.$ of $\left.10^{9} \mathrm{cfu} / \mathrm{ml}\right)$ were then added to the buccal epithelial cell-coated wells and incubated for $1 \mathrm{~h}$ at $37^{\circ} \mathrm{C}$. After washing, the bound cells were fixed by treatment with glutaraldehyde $0.25 \%$ for $10 \mathrm{~min}$ at room temperature and blocked with BSA $1 \%$ for $1 \mathrm{~h}$ at RT. Bound bacteria were detected immunologically with a pseudomonas-specific MAb (Serotec, Kidlington, Oxford) which was used at a 1 in 10000 dilution in PBS and allowed to react for $1 \mathrm{~h}$ at RT. HRP-conjugated rabbit anti-mouse IgG (Dako, High Wycombe, Bucks) was used for detection of the bound complexes, with OPD as substrate. The absorbance at $450 \mathrm{~nm}$ was measured after $30 \mathrm{~min}$ at RT with a Biotek Microplate reader. All samples were assayed in triplicate.

To assess the ability of antibodies to inhibit adhesion, $P$. aeruginosa suspensions were incubated for $1 \mathrm{~h}$ at $37^{\circ} \mathrm{C}$ with the appropriate $\mathrm{IgG}$ or $\mathrm{IgG}$ subclass fractions at a protein concentration of $0.7 \mathrm{mg} / \mathrm{ml}$. The suspensions then were washed once in PBS at $10000 \mathrm{~g}$ for $5 \mathrm{~min}$, resuspended in PBS and added to the wells coated with buccal epithelial cells. Adhesion of the bacteria to the buccal epithelial cells was then assayed as described above. The percentage inhibition of adhesion was defined as:

$$
\left(1-\frac{\mathrm{A}_{450} \text { IgG-treated sample }}{\mathrm{A}_{450} \text { control }}\right) \times 100
$$

Estimation of $P$. aeruginosa-specific IgG subclass levels

The $P$. aeruginosa suspensions used in the adhesion assays were coated directly on to microtitration plates in $100-\mu \mathrm{l}$ amounts and incubated for $1 \mathrm{~h}$ at $37^{\circ} \mathrm{C}$.
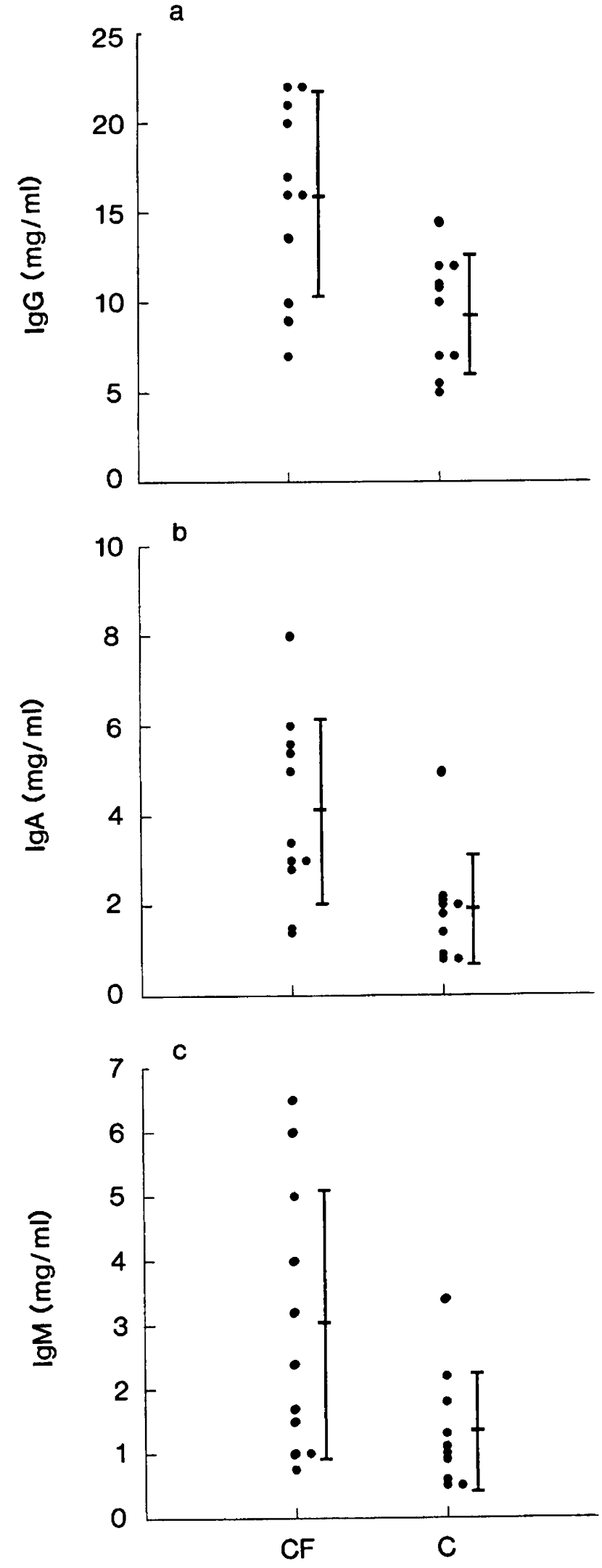

Fig. 1. Distribution of serum immunoglobulin concentrations in 11 $\mathrm{CF}$ patients $(\mathrm{CF})$ and 10 healthy controls $(\mathrm{C})$ : $\mathbf{a}, \operatorname{IgG} ; \mathbf{b}, \operatorname{IgA}$; $\mathbf{c}$, IgM. Vertical bar represents mean \pm 1 SD.

After fixing and blocking, as in the adhesion assay (above), a panel of subclass specific MAbs at "equipotent dilutions" was used to assess the amount of each subclass bound to the $P$. aeruginosa cells. 

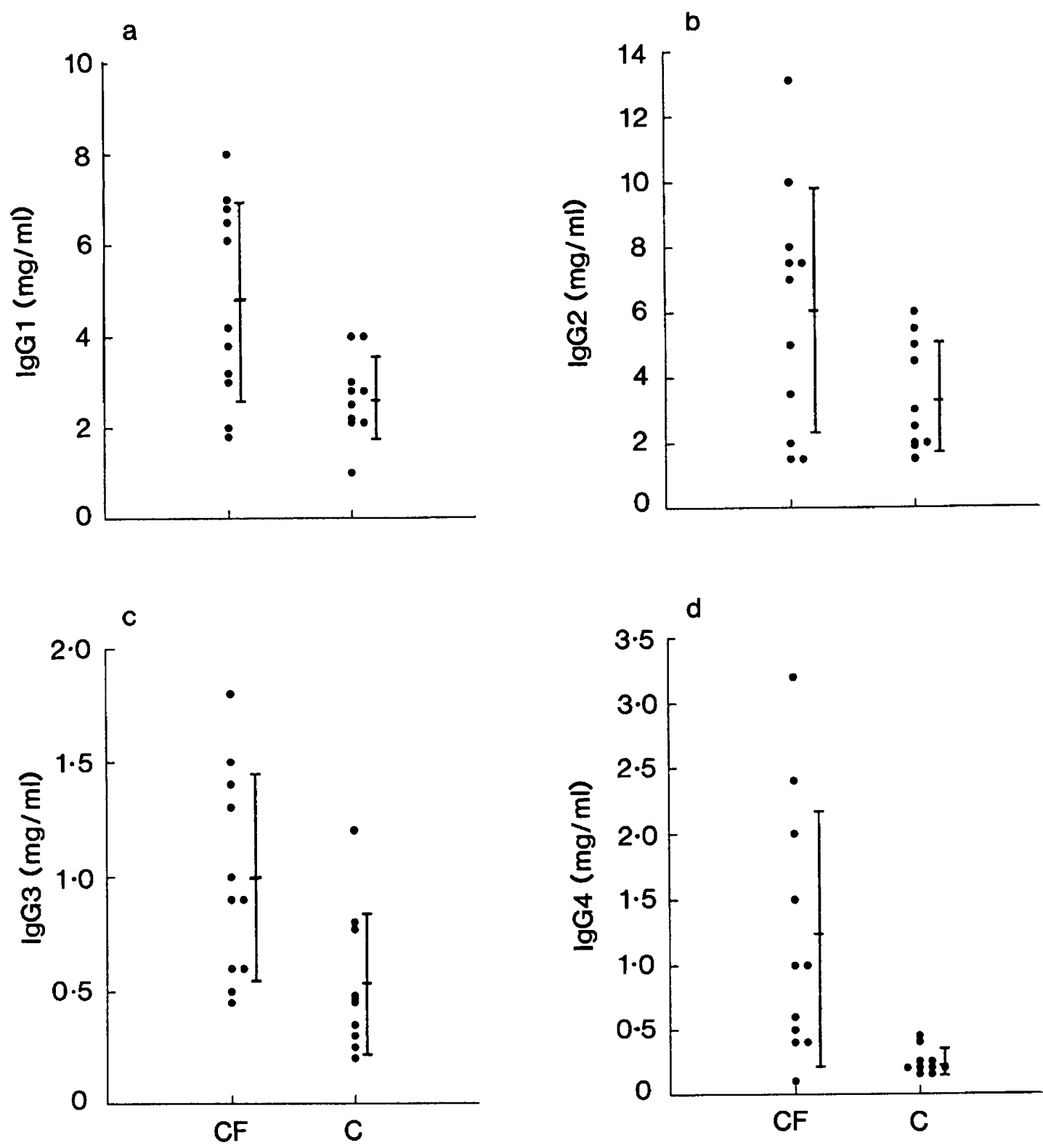

Fig. 2. Distribution of serum IgG subclass immunoglobulin concentrations in the $11 \mathrm{CF}$ patients (CF) and the 10 healthy controls (C): a, IgG1; b, IgG2; c, IgG3; d, IgG4. Vertical bar represents mean \pm 1 SD.

"Equipotent" dilutions were those that yielded comparable absorbances in binding to solid-phaseadsorbed homologous purified human IgG subclass myelomas and were: 1 in 1000 for anti-IgG1; 1 in 2000 for anti-IgG2; 1 in 2000 for anti-IgG3; 1 in 5000 for anti-IgG4. The antibodies used were Clones HP6001 (Unipath; anti-IgG1), HP6014 (Binding Site; antiIgG2), HP6010 (Unipath; anti-IgG3) and SK-44 (Sigma; anti-IgG4). Two other IgG3-specific MAbs, Clones HP6095 (Janssen, Beerse, Belgium) and HP6050 (Binding Site) were also used to confirm levels of $P$. aeruginosa-specific antibody. After incubation with these antibodies for $1 \mathrm{~h}$ at $37^{\circ} \mathrm{C}$, the plates were washed, and HRP-conjugated rabbit anti-mouse IgG antibody (Dako) was added. After incubation for a further $1 \mathrm{~h}$ at RT, the plates were washed, OPD substrate was added and absorbance was recorded at $450 \mathrm{~nm}$.

Arbitrary ELISA units were assigned in order to compare the relative responses within a set of data thus:

$$
\text { ELISA unit }=\mathrm{A}_{450} \text { (sample) } \times 10
$$

These units we used only to compare data within one assay and not to compare data obtained from different assays.

\section{Statistical analysis}

Data from the immunoglobulin isotype studies were analysed by the Mann-Whitney $U$ test, with levels of significance set at $\mathrm{p}<0.05$.

\section{Results}

Immunoglobulin isotype levels

To establish whether the hyperimmune response usually observed in CF patients was evident in the 

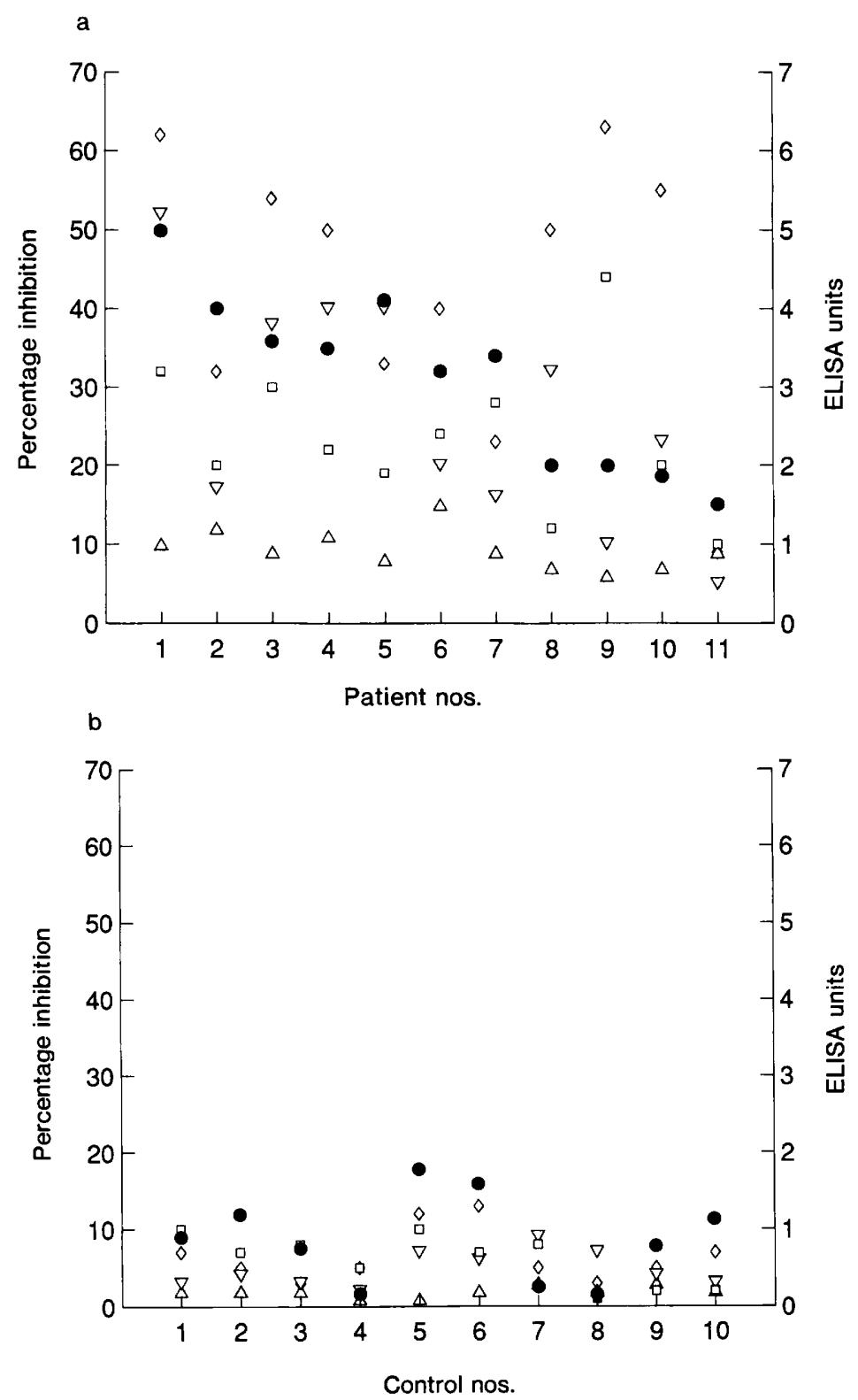

Fig. 3. Inhibition of adherence of $P$. aeruginosa to buccal epithelial cells observed after incubation with IgG from each of (a) $11 \mathrm{CF}$ patients and (b) 10 healthy controls: 1 LH scale. The estimates of $P$. aeruginosa-specific subclass antibody (in ELISA units) are also shown: IgG1 $\square, \operatorname{IgG} 2 \nabla, \operatorname{IgG} 3 \triangle$ and IgG4 $\diamond ;$ RH scale.

present study population, the total concentrations of $\mathrm{IgG}, \mathrm{IgA}$ and IgM in the CF patients and controls were estimated (fig. 1a,b and c). The levels of IgG and IgM were significantly higher in the CF group than in the control group $(\mathrm{p}<0.05)$ and the difference in $\operatorname{IgA}$ concentrations was even more marked $(p<0 \cdot 01)$. The concentration of each IgG subclass was estimated in patients and controls (fig. 2). The subclass most significantly elevated in the CF population was IgG3 $(p<0.001)$ but levels of IgG4 were also significantly raised $(p<0.01)$ as were those of IgG1 $(p<0.05)$. The IgG2 concentrations did not differ significantly ( $p>0.05$ ) between the CF and control groups.

\section{Inhibition of adhesion by purified serum IgG}

IgG was isolated from CF and control sera, and incubated with $P$. aeruginosa cells, and the adherence of the bacteria to buccal epithelial cells was then measured. The extent of inhibition of adherence obtained with IgG from the $11 \mathrm{CF}$ patients and the 10 healthy controls is shown in fig. 3. Following incubation of $P$. aeruginosa with the IgG fractions, the levels of anti- $P$. aeruginosa IgG subclass antibodies were estimated with subclass-specific MAbs. High degrees of inhibition of adherence (30-50\%) were observed with $\mathrm{IgG}$ from seven of the CF patients. IgG from the other four $\mathrm{CF}$ patients demonstrated lower inhibition levels, similar to those observed with two of the control samples. The remaining control samples gave little inhibition of pseudomonal adherence.

Estimation of $P$. aeruginosa-specific subclass antibodies identified major variation amongst patients. The levels of $P$. aeruginosa-specific IgG1, IgG2 and 


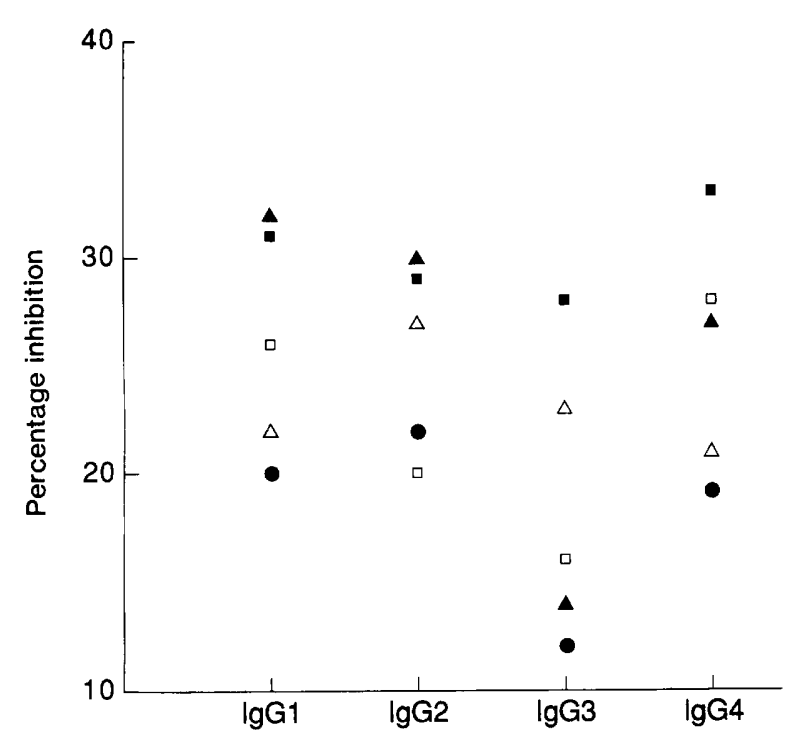

Fig. 4. Comparison of inhibition of adherence obtained with fractions enriched for IgG1, IgG2, IgG3 or IgG4 antibodies from five $C F$ patients: patient $1 \square$, patient $3 \Delta$, patient $4 \square$, patient $5 \triangle$, patient 6

IgG4 antibodies also varied from patient to patient, with some whose samples strongly inhibited the binding of $P$. aeruginosa yielding low levels of $P$. aeruginosa-specific antibodies (e.g., CF patient 2) whereas others whose samples had little effect on the binding of $P$. aeruginosa to epithelial cells had high levels of specific antibody (e.g., CF patient 9). Thus, there was no obvious association between the inhibition of bacterial adherence and the levels of $P$. aeruginosa-specific IgG subclass antibodies. Very low levels of $P$. aeruginosa-specific subclass antibodies were detected in all of the healthy controls. The levels of anti- $P$. aeruginosa IgG3 were uniformly low in both patient and control samples, as confirmed with the three different IgG3-specific MAbs tested.

\section{Comparison of IgG subclasses in inhibition of adhesion}

Fractions enriched for each of the four IgG subclasses were obtained by negative affinity chromatography and used in the adhesion model system. Similar degrees of inhibition, in the range of 2-3 inhibition units, were obtained with the fractions enriched for IgG1, IgG2 or IgG4 from all five CF patients (fig. 4). The IgG3-enriched fractions from two patients inhibited the adhesion of $P$. aeruginosa, whereas those from the other three were much less active.

\section{Discussion}

As a preliminary to this study it was appropriate to establish the overall immunoglobulin profile of the $\mathrm{CF}$ and control populations and, in particular, the IgG subclass levels, so as to eliminate the possibility that any variation in specific anti- $P$. aeruginosa antibody levels was attributable merely to a variation in the overall immune response. The CF patients investigated in this study demonstrated the variation in immune responses commonly observed in such populations, with some having markedly elevated serum immunoglobulin levels. IgG3 was particularly elevated and levels of IgG4 were also raised compared to controls. Much previous attention has been focused on the relevance of the isotypic variation in IgG subclass response to $P$. aeruginosa infection in CF. It has been suggested that elevated IgG2, a subclass with a low affinity for Fc receptors on pulmonary macrophages, could reduce clearance of $P$. aeruginosa via impaired opsonophagocytosis. ${ }^{17}$ This theory is supported by the reported correlation between elevated serum IgG2 and decreased lung function. ${ }^{11}$ Although the IgG2 levels found in this study did not differ significantly between the CF and control groups, the sample size was small.

We showed that IgG from the sera of patients with $C F$ inhibited the adherence of $P$. aeruginosa to buccal epithelial cells. Nevertheless, low degrees of inhibition were observed for some CF sera that contained high levels of anti- $P$. aeruginosa antibodies.

The immunological experience with pseudomonal infection in $\mathrm{CF}$ is that patients become hyperimmune to a wide spectrum of microbial antigens, including those implicated in adhesion, e.g., flagella, ${ }^{18}$ mucoexopolysaccharide ${ }^{19}$ and pili. ${ }^{20}$ These antibodies are responsible for the ability of the IgG fraction from $\mathrm{CF}$ patients to inhibit adhesion of $P$. aeruginosa. Those patients whose sera had little effect in the adhesion of $P$. aeruginosa and yet had levels of anti- $P$. aeruginosa antibodies similar to those of "high inhibition" patients are postulated to have had a poor immune response directed towards the particular $P$. aeruginosa antigens involved in adhesion. Those patients whose IgG fraction inhibited pseudomonal adherence only weakly were those who had low total concentrations of $\mathrm{IgG}, \operatorname{IgA}$ or $\operatorname{IgM}$ and the IgG subclasses. Continuous steroid treatment in $\mathrm{CF}$ is known to be accompanied by a decrease in antibody levels. ${ }^{21}$ Even if steroid treatment was responsible for the low total antibody levels measured in the "low inhibition" patients, it still does not explain their failure to inhibit adhesion, as the concentration of IgG used in the adhesion assay was the same for each patient and the levels of $P$. aeruginosa-specific subclass antibodies were similar for both "high" and "low" inhibition groups.

The levels of $P$. aeruginosa-specific subclass antibodies recorded were quite diverse within the group of $\mathrm{CF}$ patients. It has been suggested previously that the $\mathrm{IgG} 2$ response to microbial polysaccharide antigens is defective in CF patients ${ }^{13,22}$ but this was not apparent in the present study. High levels of LPS-specific IgG4 antibodies have been postulated to inhibit optimal pulmonary clearance of $P$. aeruginos $a .{ }^{12}$ The levels of anti- $P$. aeruginosa IgG4 recorded in this study varied amongst patients but generally were high and may have actually been detrimental rather than beneficial to the patients. Levels of anti- $P$. aeruginosa IgG3 were 
very low compared to the other subclasses, suggesting a poor IgG3 response to $P$. aeruginosa, or at least to the antigens exposed in the adhesion assay. Chronic lung disease has been reported to be associated with patient groups who have combined serum deficiencies for IgG1 and IgG3. ${ }^{23}$ Other reports have associated high anti- $P$. aeruginosa $\mathrm{IgG} 3$ titres with poor prognosis. ${ }^{24}$ These previous studies ${ }^{24}$ used a standard $P$. aeruginos $a$ antigen preparation and a different IgG3specific MAb, and so are not directly comparable with our data. In the present study, we used whole $P$. aeruginosa cells, as the emphasis was on investigating whether the nature of the IgG subclass antibodies bound to the bacteria could be correlated to the extent of inhibition of bacterial adhesion to buccal epithelial cells.

When fractions enriched for IgG1, IgG2 or IgG4 were applied in the adhesion assay, similar levels of inhibition of bacterial adherence were obtained. The five CF patients, from whose sera the subclassenriched fractions were isolated, were chosen because of the high degree of inhibition of pseudomonal adhesion observed with their IgG antibodies. If, as has been suggested, ${ }^{25,26}$ particular immunoglobulin subclasses are produced in response to the protein or polysaccharide nature of the inducing antigens, it is conceivable that individual subclasses might inhibit adherence to a homogeneous adhesin in an adhesion system. Because each of the three subclasses was capable of inhibiting adherence when used alone, albeit at a lower level than that obtained with a combination, it would suggest that the adhesin was not exclusively protein or polysaccharide in nature, or more likely, that more than one adhesin was involved. Components implicated, in the literature, as playing a part in adhesion are diverse, ranging from pili $^{6,27,28}$ to lectins ${ }^{29}$ to muco-exopolysaccharide ${ }^{8}$ to exo-enzyme S. ${ }^{9,30}$ The low inhibition of adherence obtained with IgG3 preparations suggests that the surface components that elicit the $\mathrm{IgG} 3$ response are not involved in adhesion.

It is generally accepted that the initial contact between patient and P. aeruginosa occurs in the upper respiratory tract, with colonisation by the non-mucoid form of the organism. Prevention of colonisation by this phenotype is probably more dependent on protection against adhesion of pili or outer-membrane adhesins than muco-exopolysaccharide. It is at this pre- or early stage of infection that anti-adhesion antibodies might contribute to minimising $P$. aeruginosa infection. Unfortunately, the anti-adhesion antibodies investigated here were isolated from patients with chronic infection and thus were probably not produced at a sufficiently early stage of infection to combat the huge burden facing the immune system in CF.

\section{References}

1. Ramphal R, Carnoy C, Fievre S et al. Pseudomonas aeruginosa recognizes carbohydrate chains containing type $1(\mathrm{Gal} \beta 1-3$ GlcNAc) or type 2 (Gal $\beta 1-4 \mathrm{Glc}$ NAc) disaccharide units. Infect Immun 1991; 59: 700-704.

2. Panjwani N, Zaidi TS, Gigstad JE, Jungalwala FB, Barza M, Baum, J. Binding of Pseudomonas aeruginosa to neutral glycosphingolipids of rabbit corneal epithelium. Infect Immun 1990; 58: 114-118.

3. Singh A, Hazlett LD, Berk RS. Characterization of Pseudomonas aeruginosa adherence to mouse corneas in organ culture. Infect Immun 1990; 58: 1301-1307.

4. Sajjan U, Reisman J, Doig P, Irvin RT, Forstner G, Forstner J. Binding of nonmucoid Pseudomonas aeruginosa to normal human intestinal mucin and respiratory mucin from patients with cystic fibrosis. $J$ Clin Invest $1992 ; 89: 657-665$.

5. Doig P, Sastry PA, Hodges RS, Lee KK, Paranchych W, Irvin RT. Inhibition of pilus-mediated adhesion of Pseudomonas aeruginosa to human buccal epithelial cells by monoclonal antibodies directed against pili. Infect Immun 1990; 58: $124-130$.

6. Doig P, Todd T, Sastry PA et al. Role of pili in adhesion of Pseudomonas aeruginosa to human respiratory epithelial cells. Infect Immun 1988; 56: 1641-1646.

7. Irvin RT, Doig P, Lee KK et al. Characterization of the Pseudomonas aeruginosa pilus adhesin: confirmation that the pilin structural protein subunit contains a human epithelial cell-binding domain. Infect Immun 1989; 57: 3720-3726.

8. Ramphal R, Pier GB. Role of Pseudomonas aeruginosa mucoid exopolysaccharide in adherence to tracheal cells. Infect Immun 1985; 47: 1-4.

9. Baker NR, Minor V, Deal C, Shahrabadi MS, Simpson DA, Woods DE. Pseudomonas aeruginosa exoenzyme $\mathrm{S}$ is an adhesin. Infect Immun 1991; 59: 2859-2863.
10. Winnie GB, Cowan RG. Respiratory tract colonization with Pseudomonas aeruginosa in cystic fibrosis: correlations between anti-Pseudomonas aeruginosa antibody levels and pulmonary function. Pediatr Pulmonol 1991; 10: 92-100.

11. Pressler T, Mansa B, Jensen T, Pedersen SS, Høiby N, Koch C. Increased $\mathrm{IgG} 2$ and $\mathrm{IgG} 3$ concentration is associated with advanced Pseudomonas aeruginosa infection and poor pulmonary function in cystic fibrosis. Acta Paediatr Scand 1988; 77: 576-582.

12. Moss RB, Hsu Y, Sullivan MM, Lewiston NJ. Altered antibody isotype in cystic fibrosis: possible role in opsonic deficiency. Pediatr Res 1986; 20: 453-459.

13. Shryock TR, Mollé JS, Klinger JD, Thomassen MJ. Association with phagocytic inhibition of anti-Pseudomonas aeruginosa immunoglobulin $G$ antibody subclass levels in serum patients with cystic fibrosis. J Clin Microbiol 1986; 23: $513-516$

14. Schaad UB, Lang AB, Wedgwood J, Buehlamnn U, Fuerer E. Serotype-specific serum IgG antibodies to lipopolysaccharides of Pseudomonas aeruginosa in cystic fibrosis: correlation to disease, subclass distribution, and experimental protective capacity. Pediatr Res 1990; 27: 508-513.

15. Sexton M, Reen DJ. Characterization of antibody-mediated inhibition of Pseudomonas aeruginosa adhesion to epithelial cells. Infect Immun 1992; 60: 3332-3338.

16. Persson MAA. Preparation of human sera containing one single IgG subclass using affinity chromatography. $J$ Immunol Methods 1987; 98: 91-98.

17. Hornick DB, Fick RB. The immunoglobulin G subclass composition of immune complexes in cystic fibrosis. Implications for the pathogenesis of the pseudomonas lung lesion. J Clin Invest 1990; 86: 1285-1292.

18. Anderson TR, Montie TC, Murphy MD, McCarthy VP. Pseudomonas aeruginosa flagellar antibodies in patients with cystic fibrosis. J Clin Microbiol 1989; 27 : 2789-2793.

19. Pedersen SS, Espersen F, Høiby N, Shand GH. Purification, characterization, and immunological cross-reactivity of 
alginates produced by mucoid Pseudomonas aeruginosa from patients with cystic fibrosis. J Clin Microbiol 1989; 27: 691-699.

20. Woods DE, Strauss DC, Johanson WG, Berry VK, Bass JA. Role of pili in adherence of Pseudomonas aeruginosa to mammalian buccal epithelial cells. Infect Immun 1980; 29: 1146-1151.

21. Brett MM, Ghoneim ATM, Littlewood JM. Prediction and diagnosis of early Pseudomonas aeruginosa infection in cystic fibrosis: a follow-up study. J Clin Microbiol 1988; 26: $1565-1570$.

22. Moss RB, Hsu Y, van Eede PH, van Leeuwen AM, Lewiston NJ, De Lange G. Altered antibody isotype in cystic fibrosis: impaired natural antibody response to polysaccharide antigens. Pediatr Res 1987; 22: 708-713.

23. Nilssen DE, Söderström R, Brandtzaeg $\mathrm{P}$ et al. Isotype distribution of mucosal IgG-producing cells in patients with various $\mathrm{IgG}$ subclass deficiencies. Clin Exp Immunol $1991 ; 82: 17-24$.

24. Pressler T, Pedersen SS, Espersen F, Høiby N, Koch C. IgG subclass antibodies to Pseudomonas aeruginosa in sera from patients with chronic Ps. aeruginosa infection investigated by ELISA. Clin Exp Immunol 1990; 81 : 428-434.

25. Sato $H$, Okinaga $K$. Role of pili in the adherence of Pseudomonas aeruginosa in mouse epidermal cells. Infect Immun 1987; 55: 1774-1778.

26. Saiman L, Sadoff J, Prince A. Cross-reactivity of Pseudomonas aeruginosa antipilin monoclonal antibodies with heterogeneous strains of $P$. and Pseudomonas cepacia. Infect Immun 1989; 57: 2764-2770.

27. Marcus H, Austria A, Baker NR. Adherence of Pseudomonas aeruginosa to tracheal epithelium. Infect Immun 1989; 57: 1050-1053.

28. Lingwood CA, Cheng M, Krivan HC, Woods D. Glycolipid receptor binding specificity of exoenzyme $\mathrm{S}$ from Pseudomonas aeruginosa. Biochem Biophys Res Commun 1991; 175: 1076-1081.

29. Ruths S, Driedijk PC, Weening RS, Out TA. ELISA procedures for the measurement of IgG subclass antibodies to bacterial antigens. J Immunol Methods 1991; 140: 67-78.

30. Hamilton RG. Human IgG subclass measurements in the clinical laboratory. Clin Chem 1987; 33: 1707-1725. 